\title{
Volatility among Regional Stock Markets: An Empirical Analysis
}

\author{
Nawaz Ahmad
}

\begin{abstract}
This study is an attempt to measure volatilities among regional stock markets and to establish a relationship between stock returns and volatility, and to rank these markets with respect to volatility. For this purpose, six markets are considered i.e. KSE100, Sensex, Nikkei225, Hangseng, Shanghai and Kospi. Indices' data consist of daily observations from January 2001 to August 2008. As a primary investigation, time series graph consists of historic data which has been observed depicting high correlations and a heteroskedastic patron (volatility) among the markets over the sample tenure which then formally measured and ranked by applying descriptive model of standard deviation followed by coefficient of variation which reveals that KSE has $66.23 \%$ volatility and $0.10 \%$ average return followed by Sensex, which has $63.39 \%$ volatility and $0.070 \%$ average return. Nikkei has, however, $22.19 \%$ volatility and a negative average return of $0.0024 \%$. Thereby a direct relation between volatility and stock return is established. To further validate descriptive models, an inferential statistics' model i.e. Bartlett's test is applied to investigate that there is statistically significant difference among the volatilities experienced by these stock markets and the result is significant even at $0.1 \%$ significance level.
\end{abstract}

Key words: Volatility, stock returns, regional stock markets.

\section{Introduction}

Until the mid-1980s, the KSE had a very thin volume of trade. However, between the periods of June 1987 to June 1992 market capitalization increased from Rs.31617.1 million to Rs.218357.2 and the general index of share prices increased by $155 \%$. According to a report (Economic Survey 1991-1992), these trends were due to government's liberalization policies to encourage private domestic and foreign investment, a transfer of funds that were previously tied up in the sagging real estate sector and the prospects for joint ventures with countries such as Japan, Saudi Arabia, Iran and South Korea. During this time, the profit-loss based Mudaraba securities were also introduced. These securities were permissible as per Islamic laws. This factor could have further stoked the fires of change.

The news always follows any sort of fluctuation faced by financial markets as there is always plenty to report. Wide price fluctuations are a very much normal behavior on the world's stock markets as investors keep observing any economic, business, and political events. Sometimes, the markets have been showing extremely erratic movements,

Nawaz Ahmad is an adjunct faculty member at IQRA University, Karachi, nawazahmad_pk@hotmail.com

Journal of Independent Studies and Research - MSSE

Volume $8 \quad$ Number 1 January 2010 17 
which are in no way in accordance with the information that is fed to the markets. While empirical tests of return-volatility behavior are plentiful for developed stock markets, the focus on developing and emerging stock markets has only begun in recent years. The interest in these emerging markets has risen from increased globalization and integration of world economies in general and that of financial markets in particular. The globalization and integration of these markets has created enormous opportunities for domestic and international investors to diversify their portfolios across the globe. As a result, rigorous empirical studies examining the efficiency and other characteristics of these markets would be of great benefit to investors and policy makers at home and abroad.

A number of papers (Haque and Hassan, 2000; Harvey, 1995a, b: Harvey and Bekaert, 1995; Bekaert, 1995; Bekaert and Harvey, 1997; Kim and Singal, 1999; Choudhury, 1996; Lee and Ohk, 1991; Claessens, Dasgupta and Glen, 1995) examined the returnvolatility behavior of a number of emerging market economies. Fama (1965) has found that large (small) changes in stock prices follow by large (small) changes in either signs or stock prices exhibit fatter tails than a normal distribution.

According to Schwert (1990) improvements in communications technology not only made it easy to access relevant information but provided liquidity to investors in financial markets around the world. This has led to two important changes. First, investors can get and act on information more rapidly and thus reap greater rewards. Second, since new information is now circulated more quickly, the rate at which asset prices change in response to information has also accelerated. Thus, volatility could be a symptom of a highly liquid securities market.

Alternatively, if stock markets are more volatile, there will be an uncertainty among investors which may negatively affect stock market activities. Historic episodes have taught us that extreme erraticity of stock markets ending in crashes of great speculative bubbles has eventually created difficulties in the broader economy. We are also aware that stock markets play a crucial role in the economy by channeling idle resources towards productive investments. Husain (2006) examined the causal relationship between the stock prices and the variables representing the real sector of the Pakistani economy using annual data from 1959/60 - 2004/05 and discovered that the Pakistan stock market lags economic activity. Ahmad (2007) examined the causal relationship between the stock prices and money supply in Pakistan using monthly data from December 2001 to March 2006 and discovered a uni-causal relation running from money supply to stock prices, not the other way around. Both studies indicated that the KSE is still not developed enough to be a leading indicator of economic activity as spectacular growth in stock market variables such as market capitalization, trading volume, the market index etc do not influence the economy at all. Nowadays investments in stock markets are at a higher risk, when it becomes speculatory. In last decade, many stock markets faced crashes. Current statistics show an increase in money supply in overall and in Pakistan specifically. According to Keynes, money is demanded either for transaction motive or for speculation motive. Excess money supply may lead to speculatory moves-short-term investments at stock markets in order to obtain capital gains. 
If stock markets are more volatile, there will be uncertainty among investors which may negatively affect stock market activities. According to Wagner (2007) when markets observe high volatility, it adds to the level of worry by investors as their portfolios' value violently decrease.

\section{Research Statement}

This research is conducted to measure and rank volatility in six regional stock markets under consideration and to establish a relationship through statistical framework of analysis between volatility and stock returns.

\section{Literature Review}

Volatility is a measure of spread around the mean or average return of a security. The statistical measure of standard deviation is normally used to measure volatility. Standard deviation allows an observer to judge how tightly a stock or index is grouped around an average, e.g. the moving average. A small standard deviation would mean the price is tightly bunched together. A large standard deviation means the price is spread apart. (investopedia.com) For securities, the higher the standard deviation, the greater the spread of returns and the higher the risk associated with that investment. As described by the Modern Portfolio Theory, volatility generates risk that is associated with the degree of dispersion of returns around the average. The greater the spread is from the average, the riskier the investment.

The results of a study by Schwert (1989) suggest that the contributing sources of volatility are not easily identifiable. The Schwert estimator is based on the estimation techniques proposed by Davidian and Carroll (1987) and it incorporates properties similar to the autoregressive conditional heteroskadasticity (ARCH) estimator of Engle (1982). Although volatility modeling and forecasting have proven to be extremely useful in finance, the motive behind Engle's (1982) original ARCH model was to provide a tool for measuring the dynamics of inflation uncertainty. Tools for modeling volatility dynamics have been applied in many other areas of economics and even in other areas of the social sciences, the natural sciences and medicine. Recent papers have examined the various fields in which volatility modeling and forecasting have been applied. The modeling of inflation uncertainty and its relationship with labor market variables has been studied by Rich and Tracy (2004) although this is related to Engle's (1982) earlier study.

Cipollini and Kapetanios (2004) extend their recommendation by making no prior assumption to the form of the process that underlies the common factors to allow more complicated temporal features of common factors other than non-stationarity being captured. Second type of deficiencies in simple state-space factor analysis comes from its conventional estimation method. Maximum likelihood estimation has been used to estimate common factors in the majority of the existing literature related to this topic. However, application of maximum likelihood is not feasible if we are dealing with a large dataset that includes a lot of cross-sectional series as this involves a large number of parameters being estimated. The suggestion of using principal components estimation 
for extracting common factors in an approximate dynamic factor model by Stock and Watson (2002) is a breakthrough in factor analysis with large dataset. Both of them and Bai (2003) show principal components estimation provides consistent estimates in large datasets. Bai also studies the asymptotic properties of this estimator. In particular, Cipollini and Kapetanios (2004) recommend the use of principal components method to estimate common factors from their extended multivariate stochastic volatility factor model. The study by Dolley (1933) is the first work in this area in which he examines the price effect of stock splits. His findings show that during 1921 to 1931, out of 95 splits, the price increase in 57 instances and declined in 26 cases. Two noteworthy papers in this area are Brown and Warner $(1980,1985)$ which have considered the methodological issues regarding event studies based on daily and monthly data respectively. In theoretical analysis of an event on return generating process of a firm due to an economic event, Damodaran (1985) has found two elementsthe natural event structure, i.e. the process by which nature effect the value of the firm and the information structure, i.e. the process by which the information about these events is collected and disseminated to the investor.

Meghir and Pistaferri (2004) have estimated the conditional variance of income shocks at the micro level and have discovered strong evidence of temporal variance dynamics. Volatility modeling and forecasting methods can also be put to use in agricultural economics. Ramirez and Fadiga (2003), for instance, have found evidence of asymmetric volatility patterns in U.S. soy bean, sorghum and wheat prices.

Methods for incorporating time varying volatility into interval forecasts are suggested in Granger, White and Kamstra (1989). Financial applications of probability forecasting techniques are considered in the work of Christoffersen and Diebold (2003). In traditional empirical finance literature, which is more in line of this paper, attempts are made to compute volatilities for different time intervals and to establish certain relationships with different variables.

Billson, Brailford and Hooper (2001) employ a multifactor model to select common explanatory factors for emerging markets from a set of global risk variable and local economic variables. This type of study relies on observable significance of the "proxy common factors" in accounting stock return variation within a particular model setting. However, this may be quite restrictive in the sense that if stock return fluctuations are actually driven by some unobserved common forces, then these forces will be neglected in the analysis. Another approach employs state-space representation. Common factors are defined as some unobserved components in the state-space setting. Stock and Watson $(1996,2002 a)$ call these common factors "diffusion indexes". These unobserved common factors summaries the information from a large group of driving forces that account for variation in a dataset. This group of driving forces may be generated by both macroeconomic variables and some other unobserved forces. No pre-definition of the common factors is made therefore; state-space factor analysis is relatively more flexible. 


\section{Methodology}

In order to test volatility among regional stock markets, we consider KSE 100, BSE, NIKKI, HANG SUNG, Shanghai and SEOL indices. Data consists of daily observations from January 2001 to August 2008 which has been obtained from Karachi Stock Exchange and EconStats-a web site. In order to run the data and obtain results MS Excel, SPSS, and Matrixer-a specialized econometric package are used to facilitate the research.

\subsection{Models}

As a preliminary analysis, Time series graphs are used to measure the trend, whether the data under consideration observe equal or unequal spreads, econometrically termed as "homoskedasticity" and "heteroskedasticity" respectively. Standard deviation is used as a Descriptive statistics' model for measuring the spread within each of the stock markets data over the stated tenure and is also termed as volatility in this particular case.

This descriptive statistics is further validated by applying Bartlett's test-an inferential statistics test for equality of variance whereby null hypotheses state that variances of all data sets are equal against the alternative one which states that at least one pair of variance is not equal to the rest.

\subsubsection{Descriptive}

For descriptive analysis, apart from standard deviation which gives an absolute value of spread, we have used Coefficient of Variation which gives us relative variation for each of the stock markets. On this basis, volatility in stock markets can be ranked, and will show that which market has the highest volatility. This is calculated by applying the following formula:

$$
\begin{aligned}
C V=\frac{\delta}{\bar{X}} & * 100, \text { Where } \\
C V & =\text { Coefficient of Variation, } \\
\delta & =\text { Standard Deviation, and } \\
\bar{X} & =\text { Mean. }
\end{aligned}
$$

Furthermore, stock returns play a vital and a much decisive role in stock market analysis. Since we are considering daily data for stock markets, we are getting daily returns for the markets incorporated in our sample. The computational formula for stock returns is:

$$
\begin{aligned}
& R_{t}=\ln \left(I_{t} / I_{t-1}\right), \text { where, } \\
& R_{t}=\text { stock returns at time' } t \text { ' } \\
& I_{t}=\text { stock market index at time 't' } \\
& I_{t-1}=\text { stock market index at } 1^{\text {st }} \text { lag of time ' } t \text { '. }
\end{aligned}
$$




\subsubsection{Bartlett's Test}

For inferential analysis we have used Bartlett's test (1937), Snedecor and Cochran (1989). Bartlett's test is applied to test if $\mathrm{k}$ samples have equal variances. Equal variance across samples is called homogeneity of variances. Some statistical tests, for example the analysis of variance, assume that variances are equal across groups or samples. The Bartlett test can be used to verify that assumption.

Bartlett's test is sensitive to departures from normality. That is, if distributions are non - normal which the samples under consideration belong to, then Bartlett's test may simply be testing for non-normality. It is based on statistics whose sampling distribution provides exact critical values when the sample sizes are equal. These critical values for equal sample sizes can also be used to yield highly accurate approximations to the critical values for unequal sample sizes.

$H_{0}: \delta_{1}=\delta_{2}=\ldots .=\delta_{k}$

$H_{a}: \delta_{i} \neq \delta_{j}$ For at least one pair $(i, j)$

\section{Results and Discussion}

Results followed by discussion consist of 4 phases. In the first phase a time series graph consists of historic data is discussed. In the second phase, a descriptive analysis of market indices' data consists of coefficient of variation followed by correlation analysis. Also, descriptive analysis of stock returns. In third phase, an inferential analysis is carried out for equality of variances, and finally, econometric model to validate descriptive and inferential analysis.

\subsection{Time series Graph}

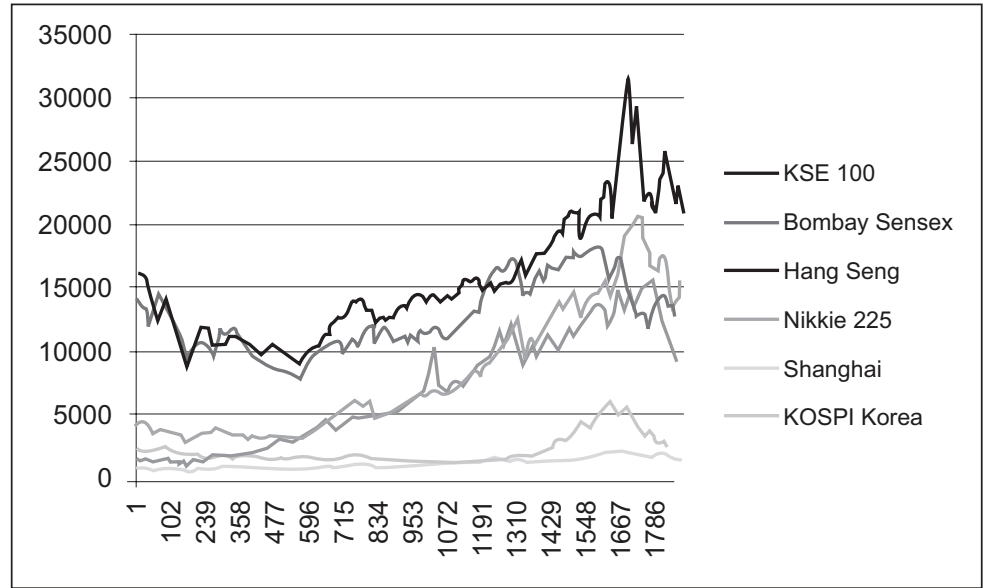

(Source: This study) 
This graph considers historic time series data for stock markets' indices which are plotted as line charts. It shows certain abrupt fluctuations in the data which dipict unequal spread or heteroskedasticity. Moreover, except two stock markets-Nikkei and Hangsengall the rest have indices below 5000 points at the begening of sample period. Furthermore, there is an evident relationship among these stock markets. If we have a look at the graph, Nikkei and Hangseng are almost overlapping and finaly get apart followed by KSE100 and Sensex.

Finally, every stock market loses investment and a substential downfall is observed in every single stock market in the end of sample period, it happens in second and third quarter of 2008 whereby the seeds of financial crunch has already been sown.

\subsection{Descriptive}

\begin{tabular}{|l|c|c|c|c|}
\hline \multicolumn{2}{c}{ Standard Deviation } & Mean & Coefficient of variation & Ranks \\
\hline KSE - 100 & 4453.2711 & 6723.6309 & $66.23312859 \%$ & 1 \\
SENSEX & 4894.61412 & 7721.8566 & $63.38649335 \%$ & 2 \\
Hang Seng & 4937.63916 & 14926.4114 & $33.07988121 \%$ & 5 \\
Nikkei 225 & 2810.26659 & 12663.37 & $22.19209097 \%$ & 6 \\
Shanghai & 1138.26428 & 2069.1265 & $55.01182649 \%$ & 3 \\
KOSPI & 421.84204 & 1039.6575 & $40.57509709 \%$ & 4 \\
\hline
\end{tabular}

(Source: This study)

An attempt is made to measure the heteroskedasticity or volatility in each of the stock markets depicted by the historic time series graph. The above table shows for each market spread about its mean index i.e., standard deviation which is further spread over its mean index so that these volatilities could be compared with each other besides the size and volume of a stock market. The descriptive statistics analysis shows that the highest volatility of $66.23 \%$ over the sample period has been observed in Karachi Stock Exchange followed by $63.39 \%$ in Bombay stock. The Hong Kong stock market is, interestingly, on second last number with $33.08 \%$ volatility despite the fact that it is a free market. Japanese stock has got the lowest volatility over the time period i.e. $22.19 \%$ against the highest volatility of $66.23 \%$.

\section{Correlations}

\begin{tabular}{|c|c|c|c|c|c|c|}
\hline & KSE 100 & Sensex & Hang Seng & Nikkei 225 & Shanghai & KosPI \\
\hline KSE 100 & 1 & & & & & \\
\hline Bombay Sensex & 0.949846 & 1 & & & & \\
\hline Hang Seng & 0.87463 & 0.959550119 & 1 & & & \\
\hline Nikkei 225 & 0.768166 & 0.765634161 & 0.75062321 & 1 & & \\
\hline Shanghai & 0.621717 & 0.747193605 & 0.7970608 & 0.61671094 & 1 & \\
\hline KOSPI Korea & 0.953998 & 0.9605371 & 0.92166852 & 0.78575092 & 0.72960285 & \\
\hline
\end{tabular}

(Source: This study) 
As depicted by historic time series graph that markets follow considerably same patterns, therefore correlation coefficients are computed as formal investigation to measure association among these stock markets. The table shows that each market has got a positive interdependence with rest of the markets.

A high volatility followed by high positive correlations is however not feasible to maintain an investment portfolio at least for risk averse person or firm.

\section{Stock Returns}

\begin{tabular}{|l|r|r|r|r|r|r|}
\hline \multicolumn{2}{r}{ KSE 100 } & \multicolumn{1}{c}{ SENSEX } & Hang Sang & Nikkei 225 & \multicolumn{1}{c|}{ Shanghai } & KOSPI \\
\hline & & & & & & \\
Average & 0.000965 & 0.000681 & 0.000189495 & $-2.4777 \mathrm{E}-05$ & $7.14 \mathrm{E}-05$ & 0.000555 \\
St. dev. & 0.01559 & 0.015554 & 0.013655136 & 0.014190963 & 0.016582 & 0.016074 \\
CV & 16.15368 & 22.83152 & 72.06053787 & -572.748240 & 232.2727 & 28.98865 \\
\hline
\end{tabular}

(Source: this study)

Like Saleem (2007), stock returns are calculated by taking natural logarithm of the ratio of market index of a day to index of the previous day [see appendix B]. Market volatility and return have always a positive relation, because riskier the market, higher are the returns. Here, KSE has got the highest average return of $0.10 \%$ over the sample period followed by SENSEX with $0.07 \%$ average return whereas Nikkei has got negative $0.0025 \%$ returns. Hence, the highest volatile market (KSE) has the highest returns followed by SENSEX and the least volatile market (Nikkei) has even negative returns.

\subsection{Inferential Analysis}

\begin{tabular}{|l|l|}
\hline \multicolumn{2}{|c|}{ Bartlett's Test } \\
SUMMARY & \\
Groups & Variances \\
KSE 100 & 19831623.47 \\
Bombay Sensex & 23957247.39 \\
Hang Seng & 24380280.46 \\
Nikkei 225 & 7897598.32 \\
Shanghai & 1295645.581 \\
KOSPI Korea & 178354.4512 \\
& \\
B Stat & 9882.194599 \\
df & 5 \\
p-value & 0.000 \\
chi-squared Critical & 11.0705 \\
\hline
\end{tabular}

(Source: This study) 
Descriptive statistics are further validated by inferential statistics whereby Bartlett's test has been applied which shows that whether the difference among volatilities observed by all stock markets is statistically significant or not. Here, test statistics i.e. 9882.19 is greater than the chi-square critical value i.e. 11.07, which refers that the null hypotheses, that all markets included in the sample have equal variance, is rejected against the alternative hypotheses that at least one pair of variances is not equal to the rest.

The rule of thumb for significance is $\alpha<\rho$, where $\alpha$ is the level of significance or probability of making type I error wherea $\rho$ is the probability value. Here, $\rho$-valueis very minute which concludes a statistically significant difference among the (variances) volatilities observed by regional stock markets.

\section{Conclusion}

This study is an attempt to measure volatilities among regional stock markets and to establish a relationship between stock returns and volatility, and to rank these markets with respect to volatility. For this purpose, six markets are considered i.e. KSE100, Sensex, Nikkei225, Hangseng, Shanghai and Kospi. Indices' data consist of daily observations from January 2001 to August 2008.

As a preliminary investigation, time series graph consists of historic data has been observed which depicts high correlations and a heteroskedastic patron (volatility) among the markets over the sample tenure which then formally measured and ranked by applying descriptive model of standard deviation followed by coefficient of variation which reveals that KSE has $66.23 \%$ volatility and $0.10 \%$ average return followed by Sensex which has $63.39 \%$ volatility and $0.070 \%$ average return. Nikkei has, however, $22.19 \%$ volatility and a negative average return of $0.0024 \%$. Thereby a direct relation between volatility and stock return is established.

To further validate descriptive models, an inferential statistics' model i.e. Bartlett's test is applied to investigate that there is statistically significant difference among the volatilities observed by these stock markets and the result is significant even at $0.1 \%$ significance level.

\section{Areas for Further Research}

Having conducted this research has given a valuable insight yet certain areas suppose to be incorporated, these are:

$$
\begin{aligned}
& \text { - } \quad \text { To incorporate GARCH model as econometric measurement of volatility } \\
& \text { - } \quad \text { To incorporate leverage effect by applying EGARCH model } \\
& \text { - } \quad \text { To compare volatility in bullish and bearish trend } \\
& \text { - } \quad \text { To follow exponential smoothening techniques and forecast } \\
& \text { - } \quad \text { To model the returns patron }
\end{aligned}
$$




\section{References}

Ahmad, Nawaz and Fazal Husain (2007), "The Relation between Stock Prices and Money Supply in Pakistan: An Investigation", Journal of Independent Studies and Research, vol. 5, no. 2, (July).

Bai, J. (2003), "Inferential theory for factor models of large dimensions", Econometrica", Vol. 71, No. 1, pp. 135-171.

Bartlett, M. S. (1937). "Properties of sufficiency and statistical tests", Proceedings of the Royal Statistical Society Series A 160, 268-282.

Bekaert G. (1995). "Market Segmentation and Investment Barriers in Emerging Equity Markets". The World Bank Economic Review.

Bekaert, G. and Campbell Harvey (1997), "Emerging Equity Market Volatility," Journal of Financial Economics, Volume 43, pp. 29-77.

Cipollini, A., and Kapetanios, G. (2004), "A stochastic variance factor model for large datasets and an application to S\&P data", Working Paper 506, Queen Mary, University of London.

Christoffersen, P.F., Diebold, F.X., (2003), Financial asset returns, direction of change forecasting, and volatility dynamics, NBER Working Paper 10009.

Davidian, M. and Carroll, R., (1987), Robust Variance Function Estimation, Journal of the American Statistical Association, Vol. 82.

Engle, R.F., (1982), Autoregressive conditional heteroskedasticity with estimates of the variance of UK inflation, Econometrica, Vol. 50, pp. 987-1008.

Haque, Mahfuzul and M. Kabir Hassan. "Stability, Predictability and Volatility of Latin American Emerging Stock Markets," University of New Orleans Working Paper, 2000.

Husain, Fazal., (2006), Stock Prices, Real Sector and the Causal Analysis: The Case of Pakistan, Journal of Management and Social Sciences, Autumn Issue, Vol. 2, No. 2, pp. 179-189.

Investopedia website; <http://www.investopedia.com/>

Karachi Stock Exchange website; http://www.kse.com.pk/

Lee, Sang, and Ki Ohk. 1991. "Time -varying Volatilities and Stock market returns: International evidence". Pacific-Basin Capital Markets Research. 
Meghir, C. and Pistaferri, L., (2004), Income variance dynamics and heterogeneity, Econometrica, Vol. 72, pp. 1-32.

Ramirez, O.A. and Fadiga, M., (2003), "Forecasting agricultural commodity prices with asymmetric error GARCH models", Journal of Agricultural and Resource Economics, Vol. 28, pp. 71-85.

Rich, R., Tracy, J., (2004). "Uncertainty and labor contract durations", Review of Economics and Statistics, Vol. 86, pp. 270-287.

Saleem, K., (2007). "Modeling volatility and asymmetries of KSE", www.ssrn.com

Schwert, G.W., 1990. "Stock market volatility", Financial Analysis Journal, May-June Issue, pp. 23-34.

Schwert, G.W. (1998), "Stock Market Volatility: Ten Years After the Crash" BrookingsWharton Papers on Financial Services, Washington, DC: Brookings Institution.

Snedecor, George W. and Cochran, William G. (1989), Statistical Methods, lowa State University Press.

Stock, J. H., and Watson, M. W. (2002a), "Macroeconomic forecasting using diffusion indexes", Journal of Business and Economic Statistics, Vol. 22, No. 2, pp. 147-162.

Stock, J. H., and Watson, M.W. (2002b), "Forecasting using principal components from a large number of predictors", Journal of the American Statistical Association, Vol. 97, No. 460.

Wagner, Hans., 2007. "Volatility as a Stock market indicator", www.tradingonlinemarkets.com, August 27. 


\section{Appendix A}

Individual stock markets' prices are shown with the best fit, so that each market series' patron could be observed independently.
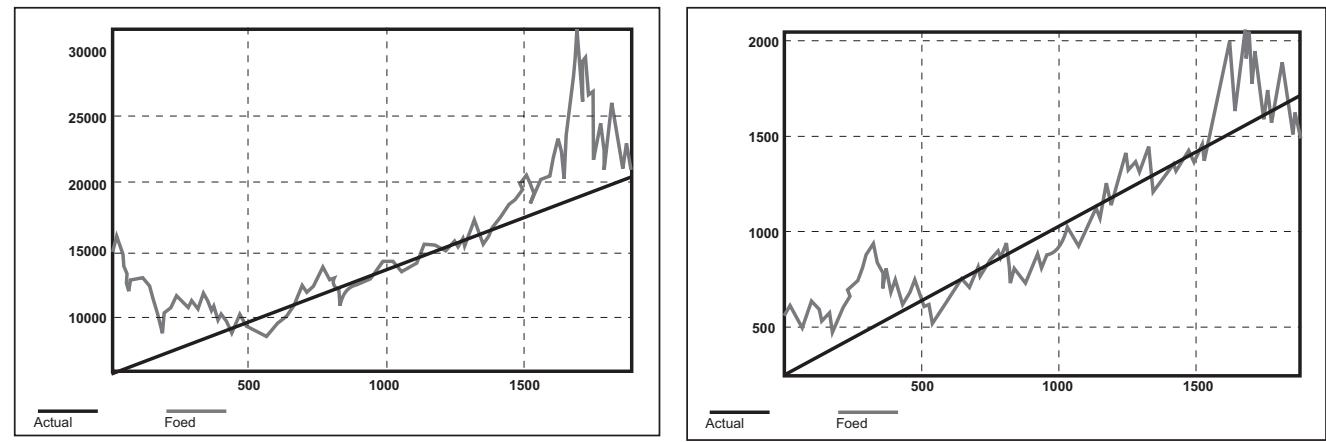

Hangseng

Kospi
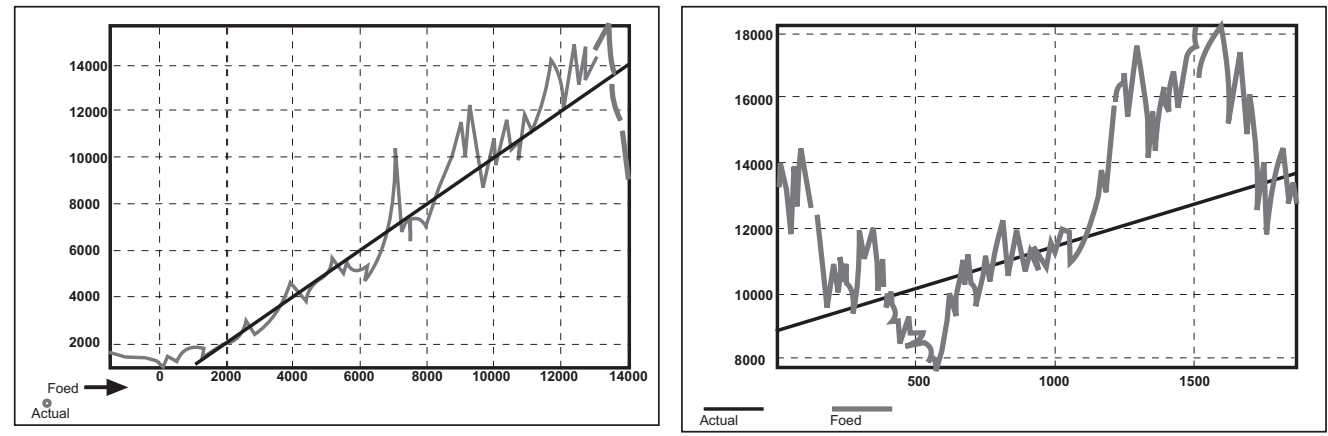

Kse100

Nikkei
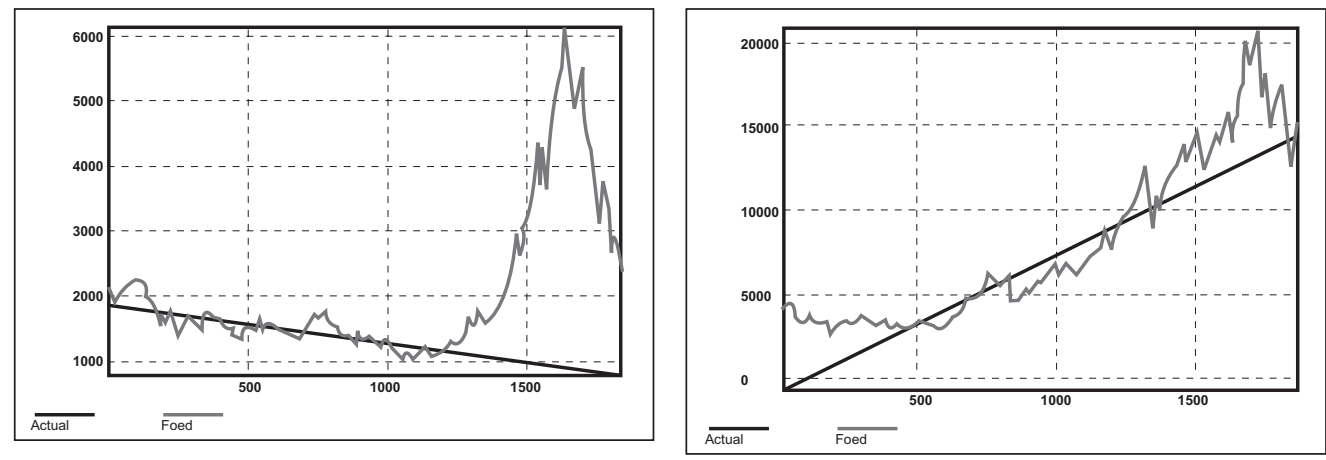

Shenghai

\section{Seneex}

